\title{
DETERMINATION OF LOAD TEST CONDITIONS FOR RAIL FASTENINGS OF A FLOATING SLAB TRACK
}

\author{
SHINGO TAMAGAWA \\ Department of Track Structures \& Components, Railway Technical Research Institute, Japan.
}

\begin{abstract}
In Japan, rail fastenings are required to be checked for their performance by the static loading test. The test is generally performed in the laboratory under the biaxial static loading conditions. The values of the loads and loading angles are determined by using the FEM model of the track. The author has developed the FEM model of a general slab track to determine the loads and loading angles for the laboratory test of rail fastenings. However, the conventional FEM model cannot be applied to the floating slab track. Therefore, in this study, the author has developed a FEM model of the floating slab track and proposes the determination method of load conditions based on a FEM analysis. Results showed that the determination method based on the FEM model can evaluate the performance of rail fastenings of the floating slab track with a higher accuracy than before.
\end{abstract}

Keywords: FEM model, floating slab track, laboratory test, rail fastenings.

\section{INTRODUCTION}

In Japan, rail fastenings are required to be checked for their performance by the static loading test at a laboratory (hereafter, laboratory test) [1]. The laboratory test is generally performed under the biaxial static loading conditions as shown in Fig. 1. The loading conditions, such as the values of the loads and loading angles, are determined by the FEM analysis. In the FEM analysis, the loads which are dispersed by the track [2] are calculated. The dispersed design loads are composed of vertical rail pressures, lateral rail pressures and rail tilting moments. The dispersed loads have been calculated by the practical solution based on the torsion theory $[3,4]$. However, the conventional torsion theory cannot sufficiently reproduce the loading test results. It is deemed that the test accuracy may deteriorate when the laboratory test is performed under the loading condition based on the conventional torsion theory. Therefore, the FEM model of a general slab track has been developed and a method for

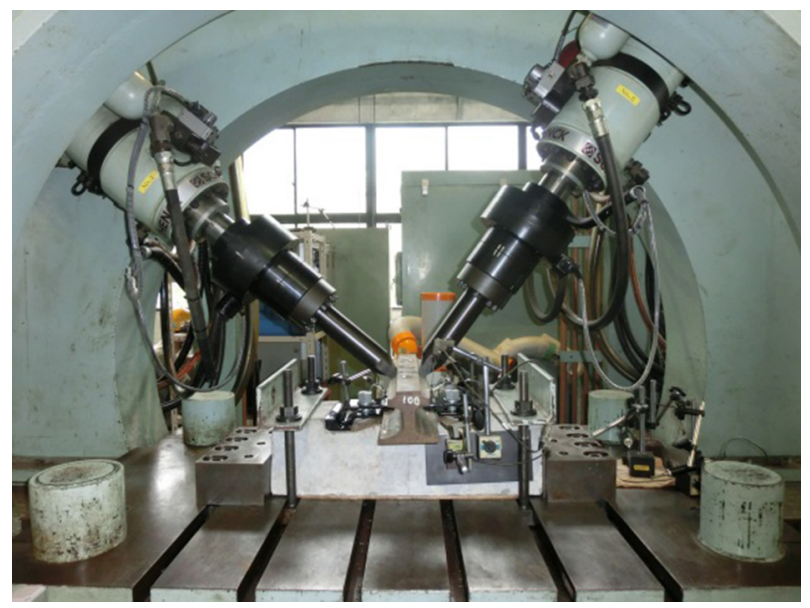

Figure 1: Static loading tests. 


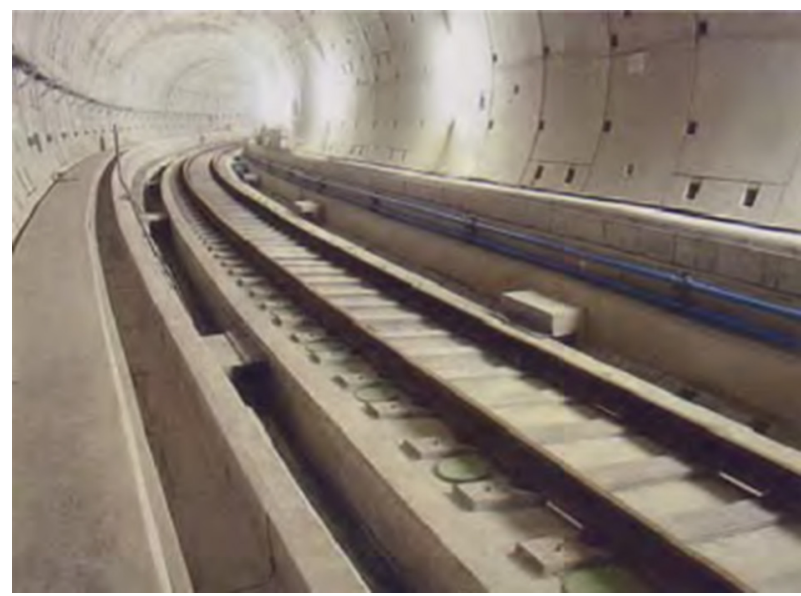

Figure 2: Floating slab tracks (JRCC [7]).

determination of the load conditions has been proposed [5, 6]. However, the FEM model of the general slab track cannot be applied to the floating slab track because the floating slab track is supported by the softer coil springs and has longer slabs than those of the general slab tracks as shown in Fig. 2. Therefore, the FEM model of a general slab track cannot simulate the motion of the floating slab track enough and cannot calculate the dispersed forces mentioned above with a high accuracy.

For the reasons mentioned above, the author developed the FEM model of the floating slab track for determining the load conditions of laboratory test and performed the laboratory test. This paper is the advanced version of the conference paper [8].

\section{PROPOSED FEM MODEL}

\subsection{Proposed model}

The proposed FEM model of a floating slab track and the meshing of the model are shown in Figs 3 and 4. The FEM model is composed of spring elements, plate elements and solid elements. Two floating slabs $(L=19,980 \mathrm{~mm} \times 2$ slabs $)$ are modelled by plate elements and are supported by 32 coil springs, which are spaced at $1250-\mathrm{mm}$ intervals. The rail is JIS-50 kg N type and is modelled by solid elements and supported by 64 rail fastenings, which are spaced

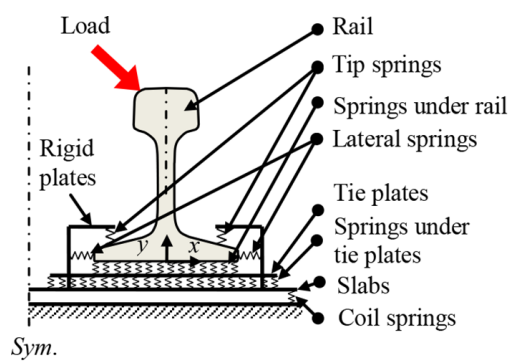

(a) Front view of the model.

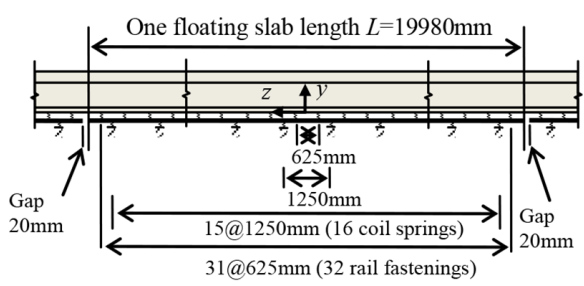

(b) Side view of the model.

Figure 3: Proposed model of floating slab tracks. 


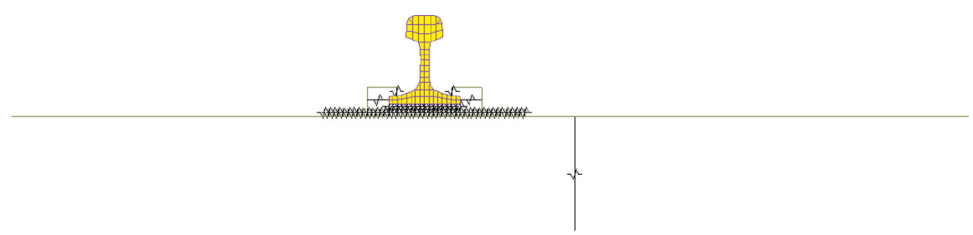

(a) Front view of the model.

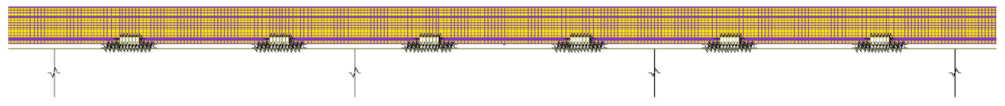

(b) Side view of the model.

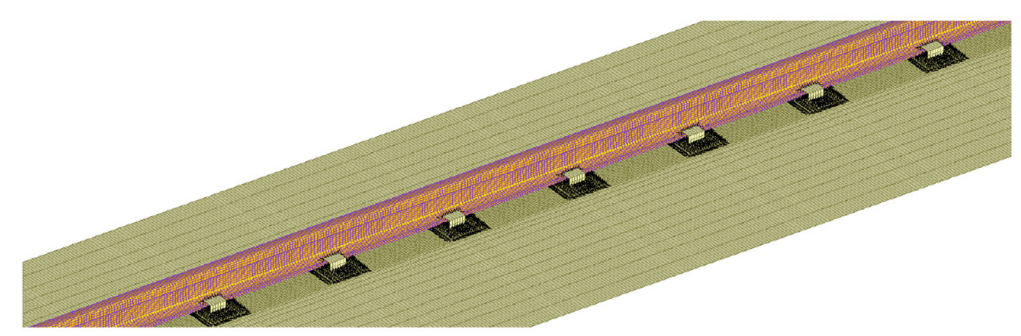

(c) Overhead view of the model.

Figure 4: FEM meshing of the model.

at $625-\mathrm{mm}$ intervals. The rail clips are divided into two parts, such as lateral springs and tip springs, and are modelled by spring elements with non-linear elasticity. The steel tie plates which support the rail are modelled by plate elements. The springs under the rail and under the tie plates are modelled by spring elements with non-linear elasticity. The load is composed of wheel load and lateral load, and is loading on the rail head from the field corner of the rail. In general, rail fastenings are designed under the condition that lateral loads of equal magnitude and opposite direction, respectively, act on the right rail and the left one located just above the target rail fastenings. This loading condition is severe because the effect of springs that support the rail supporter sideward is cancelled by each other, and the effect of dispersion of lateral loads is reduced. Under this loading condition, the right rail and the left one deform symmetrically and the slabs can move only up and down. For this reason, only a single rail is modelled and the lateral displacement and the rotation of the slabs can be ignored. The FEM analyses shown in this study are performed by the NASTRAN.

\subsection{Spring coefficients}

Figure 5 shows the rail fastening to which this study applies. In order to evaluate the characteristics of the rail fastening and to incorporate into the spring elements of the proposed FEM model, the spring coefficients of the rail fastening were measured. The measuring of the spring coefficients was based on the test procedure [9]. Figure 6 shows the test arrangement for the coefficient of the spring under the rail and the tie plate. Figures 7 and 8 show the test arrangement for the coefficient of the tip spring and the lateral springs. The details of the test procedure are described in the conference paper [8]. With regard to the results obtained by 


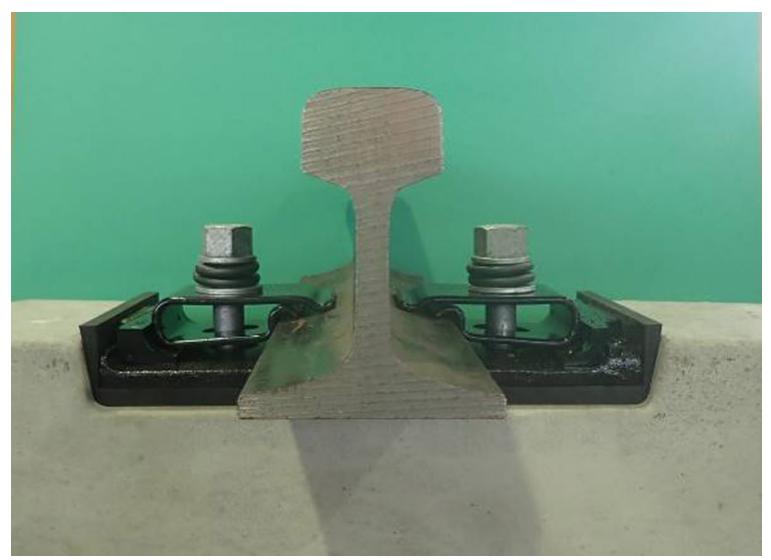

Figure 5: Rail fastening.

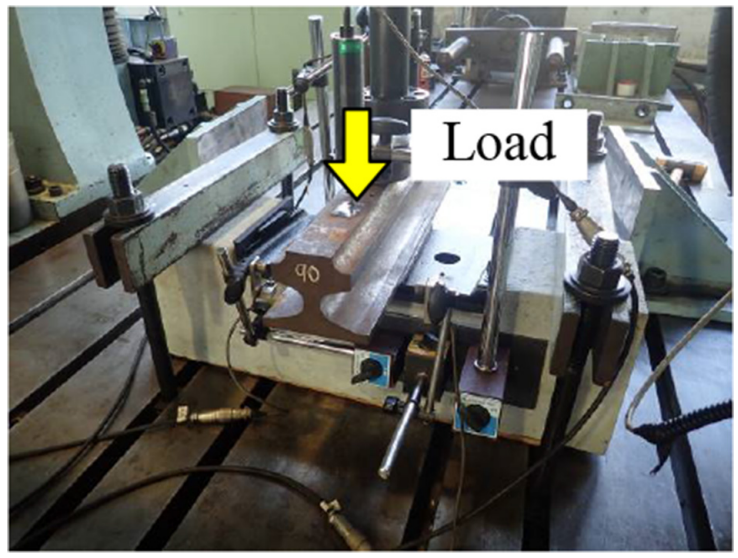

Figure 6: Test osf spring under rail and tie plate.

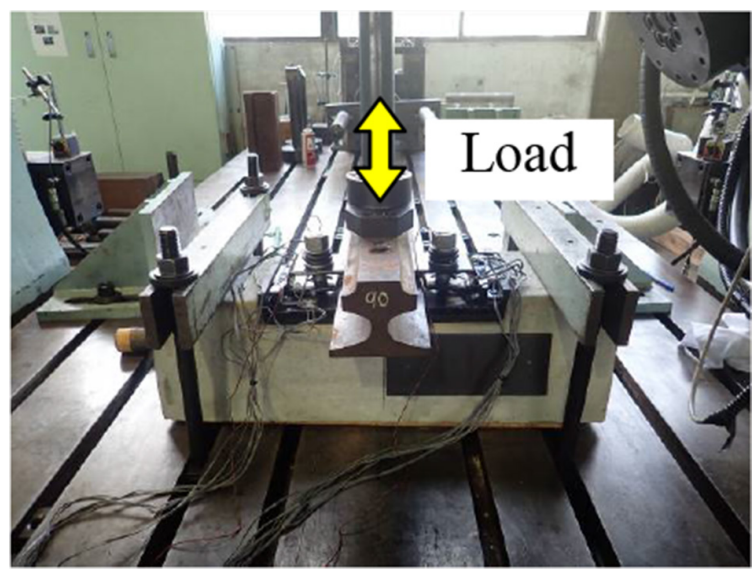

Figure 7: Tests of tip spring. 


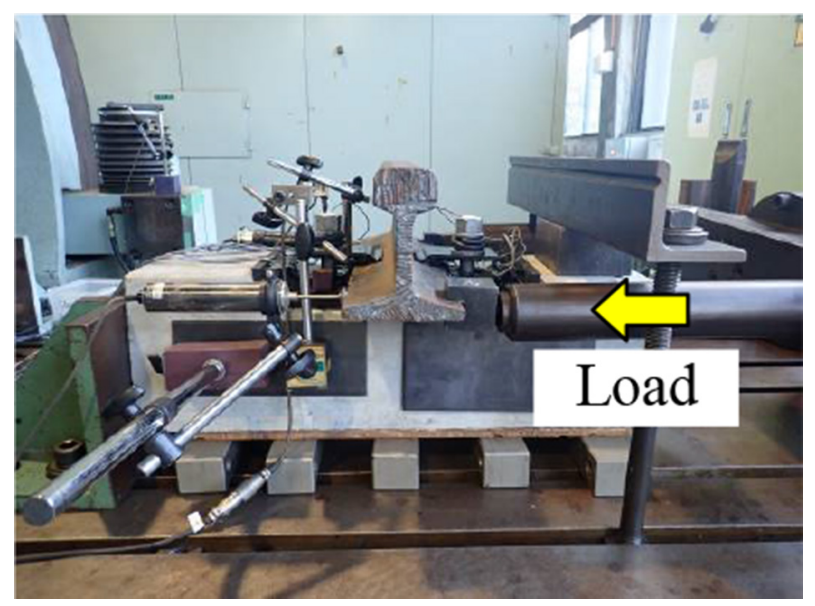

Figure 8: Tests of lateralspring.

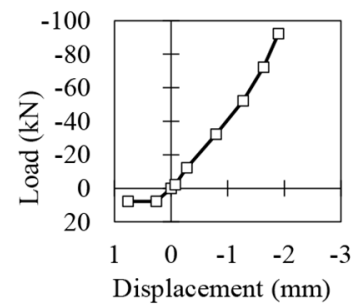

(a) Springs under rail.

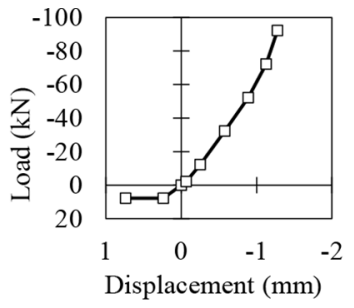

(b) Springs under tie plate.

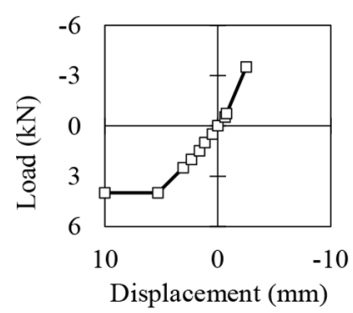

(c) Tip springs.

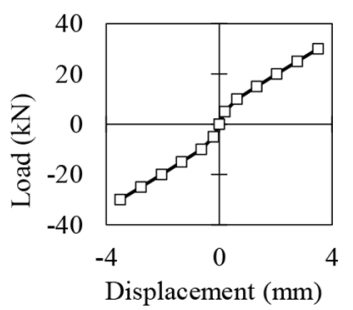

(d) Lateral springs.

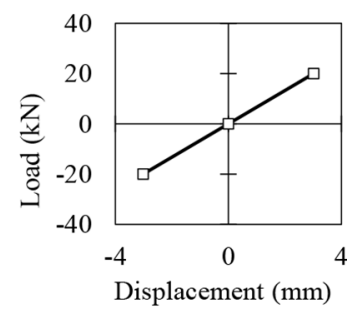

(e) Coil springs.

Figure 9: Characteristics of springs.

measuring the coefficients, Fig. 9 shows the relationships between the forces and the displacements obtained in the test.

\subsection{Load cases}

Loads applied for the analyses are the designed loads used for checking the safety of rail fastenings of the metre-gauged line. The design loads which are composed of wheel loads and lateral loads are calculated with the half of axle load $150 \mathrm{kN}$ and with the coefficients of wheel and lateral variations as shown in Table 1 . The loads A are the maximum values which rarely occur on the site, and the loads B are the average values which occur in the normal conditions. 
Table 1: Design loads of rail fastenings.

\begin{tabular}{llll}
\hline Loads & Alignment & $\begin{array}{l}\text { Loads A (the maximum } \\
\text { values) }\end{array}$ & $\begin{array}{l}\text { Loads B (the average } \\
\text { values) }\end{array}$ \\
\hline Wheel loads & $\begin{array}{l}\text { Tangent and } \\
\text { curved }\end{array}$ & $150 \mathrm{kN} \times 1 / 2 \times 1.3=98 \mathrm{kN}$ & $150 \mathrm{kN} \times 1 / 2 \times 1.15=86 \mathrm{kN}$ \\
Lateral loads & $\mathrm{R}<600 \mathrm{~m}$ & $150 \mathrm{kN} \times 1 / 2 \times 0.8=60 \mathrm{kN}$ & $150 \mathrm{kN} \times 1 / 2 \times 0.4=30 \mathrm{kN}$ \\
\hline
\end{tabular}

The axle load: $150 \mathrm{kN}$.

The coefficients of wheel variations: 1.3 at loads A, 1.15 at loads B.

The coefficients of lateral variations: 0.8 at loads A, 0.4 at loads B.

Table 2: Load cases of FEM analyses.

\begin{tabular}{lllll}
\hline Cases & Loads & $\begin{array}{l}\text { Wheel loads } \\
(\mathbf{k N})\end{array}$ & $\begin{array}{l}\text { Lateral loads } \\
(\mathbf{k N})\end{array}$ & $\begin{array}{l}\text { Loading positions } \\
(\text { Fig. 10) }\end{array}$ \\
\hline a1 & Loads A & 98 & 60 & Centre of the slab \\
b1 & Loads B & 86 & 30 & \\
a2 & Loads A & 98 & 60 & Ends of the slab \\
b2 & Loads B & 86 & 30 & \\
\hline
\end{tabular}

The loads are applied on the rail in four cases as shown in Table 2. The cases are set for the combination of loads and loading positions. The loading positions are the centre of the slab and the ends of the slab as shown in Fig. 10.

\subsection{FEM results}

FEM analyses of four cases (Case a1, b1, a2 and b2) were carried out. With regard to FEM results, Figs 11-13 show the distribution of rail head displacements, rail base displacements and rail tilting angles.

From the FEM analyses, vertical rail pressures $W$, lateral rail pressures $H$ and rail tilting moments $M$ were estimated as follows. Figure 14 shows the relationship between external forces and reaction forces of the FEM model.

$$
\begin{gathered}
W=\sum_{i=-n}^{n}\left(W_{i}\right)-\left(P_{l}+P_{r}\right) \\
H=R_{l}+R_{r} \\
M=\sum_{i=1}^{n}\left(W_{i} \cdot b_{i}\right)-\sum_{i=-n}^{-1}\left(W_{i} \cdot b_{i}\right) \\
+\left(P_{l} \cdot d_{l}-P_{r} \cdot d_{r}\right)+\left(R_{l}+R_{r}\right) \cdot c
\end{gathered}
$$

Figures 15-17 show the vertical rail pressures, lateral rail pressures and rail tilting moments, respectively. Vertical and lateral rail pressures are the dispersed forces that act on a single rail fastening when the wheel loads and lateral loads described in Table 2 act on the track model. Rail tilting moments are the moments by rail tilting that act on a single rail 


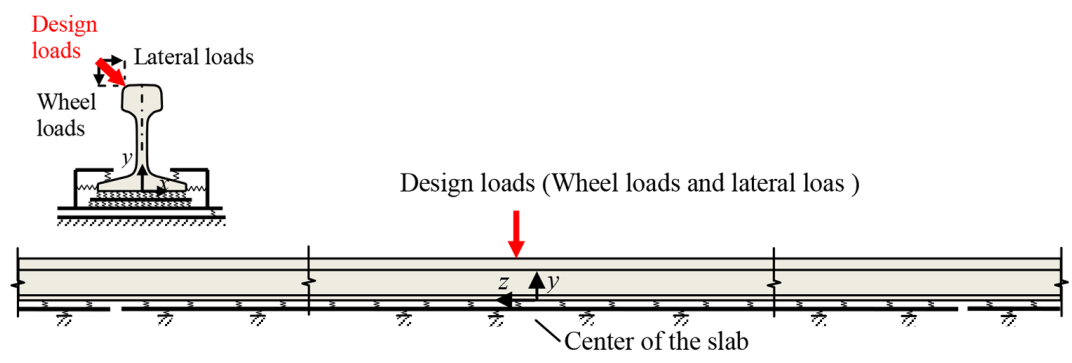

(a) Load on the center of the slab (Case a1, b1).

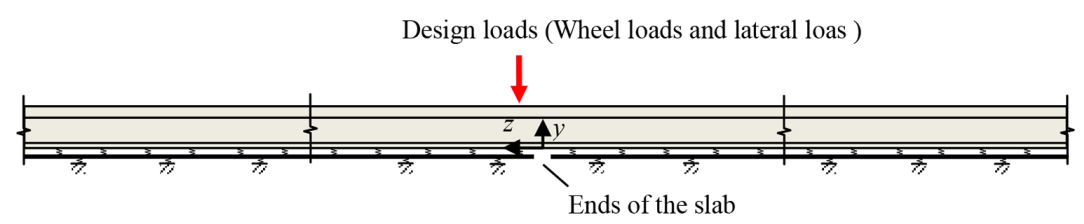

(b) Load on the ends of the slab (Case a2, b2).

Figure 10: Loading position of FEM analyses.

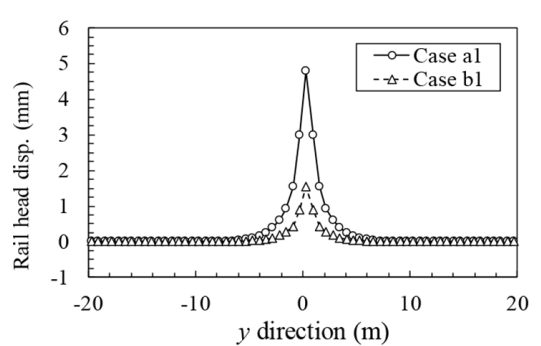

(a) Case al and bl

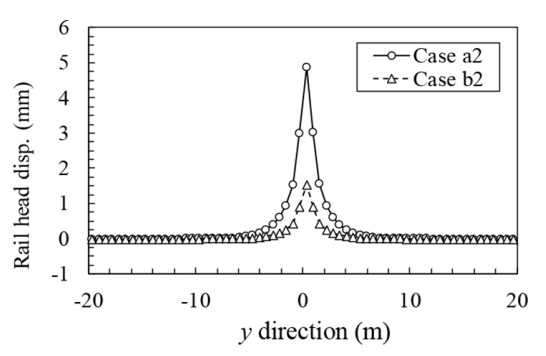

(b) Case $\mathrm{a} 2$ and b2

Figure 11: Distribution of rail head displacements.

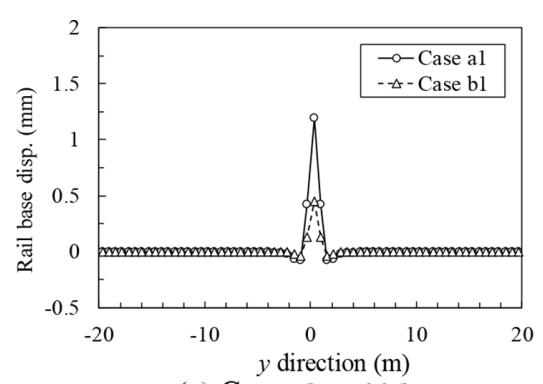

(a) Case al and bl

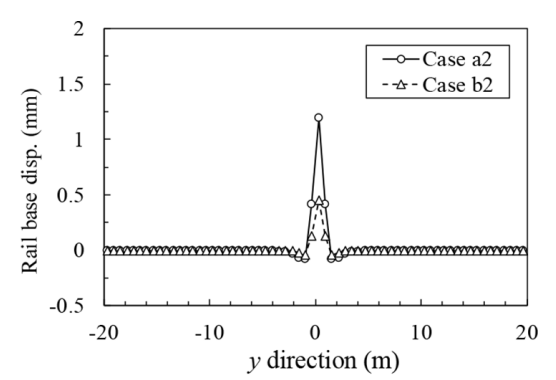

(b) Case a2 and b2

Figure 12: Distribution of rail base displacements.

fastening and are defined around the central point of the rail bottom surface. Table 3 shows the rail displacements and dispersed loads.

As shown in Table 3, the vertical rail pressures obtained from Case a1 and b1 are larger than those of Case a2 and b2. This is because the stiffness of rail supports at the ends of slab is smaller and the dispersion effect is higher than that at the centre of the slab. These effects result in the rail tilting angles obtained from Case a2 being larger than those of Case a1. 


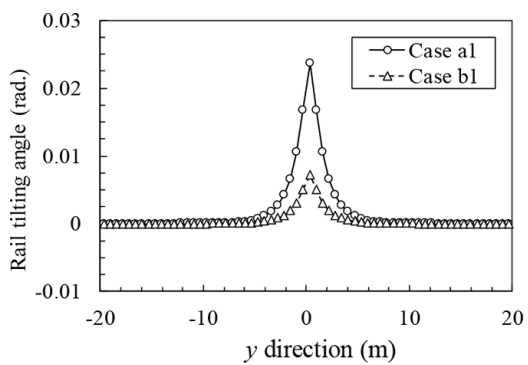

(a) Case al and bl

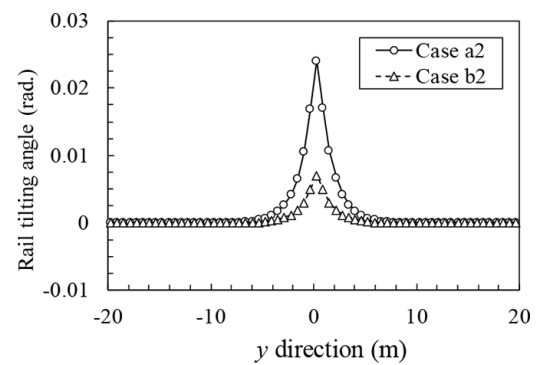

(b) Case $\mathrm{a} 2$ and b2

Figure 13: Distribution of rail tilting moments.

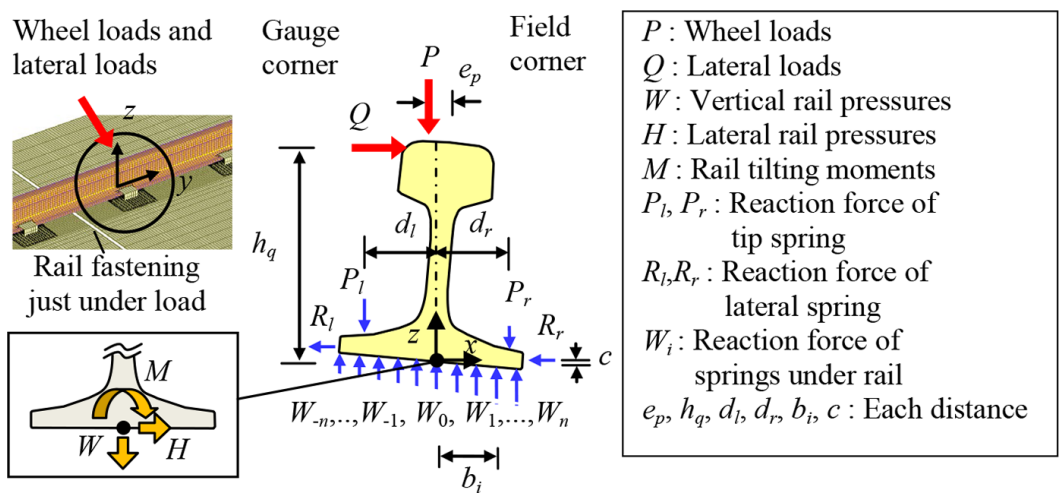

Figure 14: External forces and reaction forces of the FEM model.

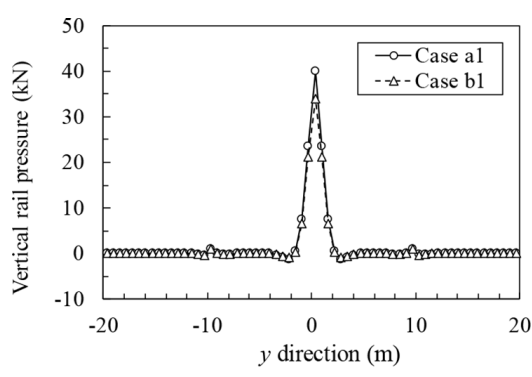

(a) Case $\mathrm{a} 1$ and b1

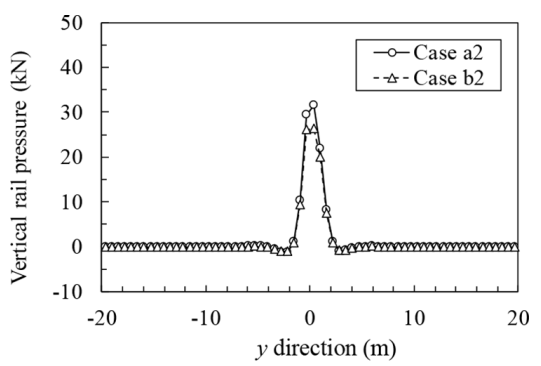

(b) Case $\mathrm{a} 2$ and $\mathrm{b} 2$

Figure 15: Distribution of vertical rail pressures.

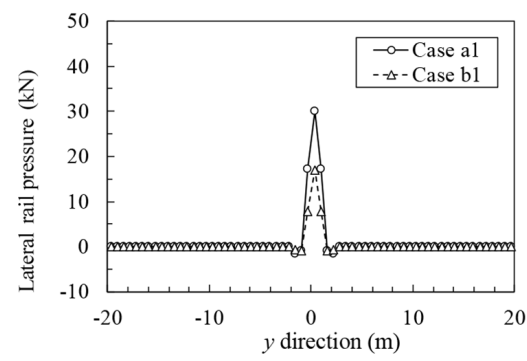

(a) Case al and bl

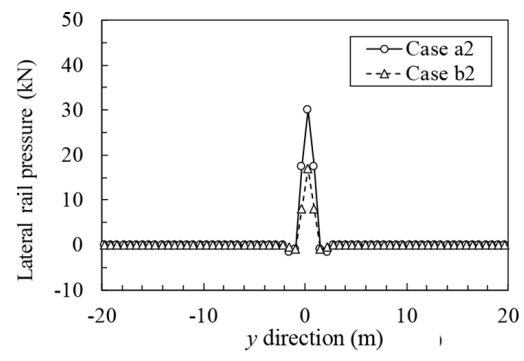

(b) Case a2 and b2

Figure 16: Distribution of lateral rail pressures. 


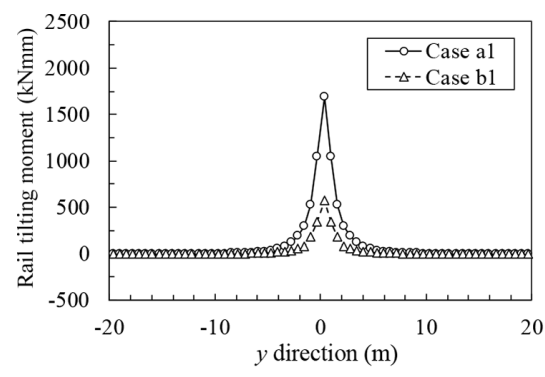

(a) Case al and b1

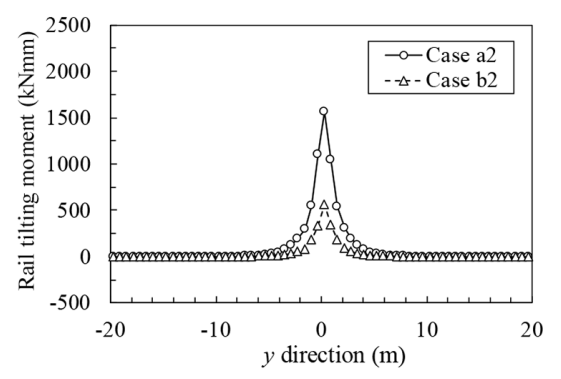

(b) Case a2 and b2

Figure 17: Distribution of lateral rail tilting moments.

Table 3: FEM results of the rail displacements and dispersed loads at the loading position.

\begin{tabular}{|c|c|c|c|c|c|}
\hline Items & Unit & Case a1 & Case b1 & Case $\mathbf{a} 2$ & Case b2 \\
\hline $\begin{array}{l}\text { Rail head } \\
\text { displacements }\end{array}$ & $\mathrm{mm}$ & 4.81 & 1.54 & 4.88 & 1.54 \\
\hline $\begin{array}{l}\text { Rail base } \\
\text { displacements }\end{array}$ & $\mathrm{mm}$ & 1.20 & 0.45 & 1.20 & 0.45 \\
\hline Rail tilting angles & rad. & 0.0236 & 0.0071 & 0.0241 & 0.0071 \\
\hline $\begin{array}{l}\text { Vertical rail } \\
\text { pressures }\end{array}$ & $\mathrm{kN}$ & 40.1 & 33.9 & 31.6 & 26.3 \\
\hline Lateral rail pressures & $\mathrm{kN}$ & 30.1 & 17.0 & 30.1 & 17.0 \\
\hline Rail tilting moments & $\mathrm{kN} \mathrm{mm}$ & 1688 & 567 & 1567 & 564 \\
\hline
\end{tabular}

\section{DETERMINATION OF LOAD CONDITIONS}

This section shows the method for determining the loading conditions, such as the values of load and the loading angles of the laboratory test, based on the dispersed loads obtained from FEM results.

\subsection{Determination method of load condition}

Figure 18 shows the biaxial loading condition of the laboratory test. Test loads $L_{A}$ and $L_{B}$, the angles of load application $\theta_{A}$ and $\theta_{B}$ and the height of load application $h$ are expressed by the following equations:

$$
\begin{gathered}
L_{A}=\sqrt{\left(W_{A}-L_{0} \sin \theta_{B}\right)^{2}+\left(H_{A}+L_{0} \cos \theta_{B}\right)^{2}} \\
L_{B}=\sqrt{\left(W_{B}-L_{0} \sin \theta_{A}\right)^{2}+\left(H_{B}+L_{0} \cos \theta_{A}\right)^{2}} \\
\theta_{A}=\tan ^{-1}\left(\frac{W_{A}-L_{0} \sin \theta_{B}}{H_{A}+L_{0} \cos \theta_{B}}\right) \\
\theta_{B}=\tan ^{-1}\left(\frac{W_{B}-L_{0} \sin \theta_{A}}{H_{B}+L_{0} \cos \theta_{A}}\right)
\end{gathered}
$$


Gauge corner Field corner

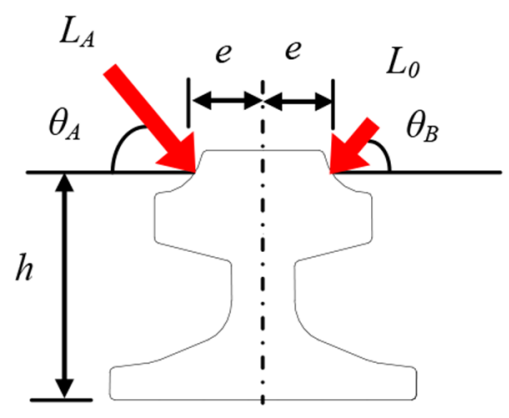

(a) Load-A.
Gauge corner Field corner

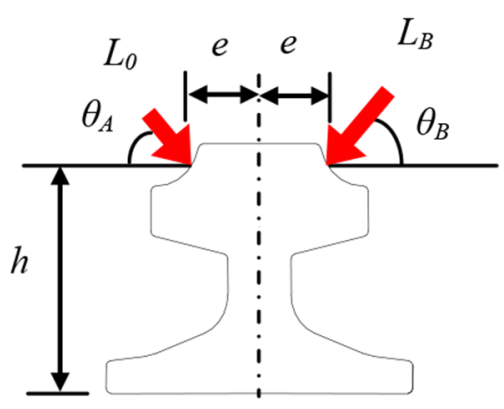

(b) Load-B.

Figure 18: Bi-axial static load test.

$$
\begin{aligned}
& h=\frac{M_{A}+e\left(W_{A}-2 L_{0} \sin \theta_{B}\right)}{H_{A}} \\
& h=\frac{M_{B}+e\left(W_{B}-2 L_{0} \sin \theta_{A}\right)}{H_{B}}
\end{aligned}
$$

Here, $W_{A}, H_{A}$ and $M_{A}$, or $W_{B}, H_{B}$ and $M_{B}$ are vertical rail pressures, lateral rail pressures and rail tilting moments calculated by eqns (1), (2) and (3), respectively. The subscripts $A$ and $B$ indicate the design loads $\mathrm{A}$ and $\mathrm{B}$, respectively. $L_{0}$ is the minimum load applied in the opposite direction to $L_{A}$ or $L_{B}$ and is set at 5-10 kN. The height $h$ and the distance $e$ are determined by the size of test rail. Thus, any two of the parameters, $W_{A}, W_{B}, H_{A}, H_{B}, M_{A}$ or $M_{B}$, become independent variables. Here, $H_{A}$ and $H_{B}$ are selected as the independent variables to solve eqns (4)-(9). In this case, using $h$ and $e$ of the test rail owned by the laboratory, the equations can be solved by the following steps:

a. Set $\theta_{A}{ }^{*}\left(0^{\circ} \leq \theta_{A}{ }^{*} \leq 90^{\circ}\right)$ as an assumed value of $\theta_{A}$ and substitute $\theta_{A}{ }^{*}$ into eqn (9) to calculate the temporary value $H_{B}{ }^{*}$.

b. Substitute $\theta_{A}{ }^{*}$ and $H_{B}{ }^{*}$ into eqn (7) to calculate the temporary value $\theta_{B}{ }^{*}$.

c. Substitute $\theta_{B}{ }^{*}$ into eqn (8) to calculate the temporary value $H_{A}{ }^{*}$.

d. Substitute $H_{A}{ }^{*}$ and $\theta_{B}{ }^{*}$ into eqn (6) to calculate the value $\theta_{A}$.

e. Steps a-d are repeated until $\theta_{A}$ coincides with the assumed value $\theta_{A}{ }^{*}$ and then $\theta_{A}{ }^{*}$ is determined as $\theta_{A}$.

f. Calculate $H_{B}$ from eqn (9), $\theta_{B}$ from eqn (7) and $H_{A}$ from eqn (8).

g. Calculate $L_{A}$ and $L_{B}$ from eqns (4) and (5).

The ideal height of the test rail can be determined when $H_{A}$ and $H_{B}$ calculated above become closest to the $H_{A}$ and $H_{B}$ calculated from eqn (2).

\subsection{Calculation results}

By using the method discussed in the previous section, the loading condition can be obtained as shown in Table 4. Hereafter, Case 1 refers to the case in which the loading position is the centre of the slab and Case 2 refers to the case in which the loading position is the ends of the slab. $L_{0}$ and $e$ are set at $5-10 \mathrm{kN}$ and $30 \mathrm{~mm}$, respectively. 
Table 4: Load conditions of laboratory test.

\begin{tabular}{llll}
\hline & & \multicolumn{2}{c}{ Loading positions } \\
Items & Unit & Case 1: Centre of the slab & $\begin{array}{l}\text { Case 2: Ends of the slab } \\
\text { (Case a2 and b2) }\end{array}$ \\
\hline$L_{A}$ & $\mathrm{kN}$ & 48.9 & 42.0 \\
$L_{B}$ & $\mathrm{kN}$ & 35.2 & 29.3 \\
$\theta_{A}$ & Degrees & 41.4 & 41.2 \\
$\theta_{B}$ & Degrees & 50.7 & 51.6 \\
$e$ & $\mathrm{~mm}$ & 80 & 80 \\
$h$ & $\mathrm{~mm}$ & 30 & 30 \\
$L_{0}$ & $\mathrm{kN}$ & 10 & 5 \\
\hline
\end{tabular}

Case 1: The loading position is the centre of the slab; the combination of Case a1 and b1. Case 2: The loading position is the ends of the slab; the combination of Case a2 and b2.

\section{LABORATORY TEST AND VALIDITY OF THE DETERMINATION METHOD}

In order to verify the validity of the determination method described in the previous section, the laboratory tests were carried out in two cases (Case 1 and Case 2).

\subsection{Test procedure}

Figure 19 shows the laboratory test arrangement under biaxial loading condition. JIS-50 kg $\mathrm{N}$ test rails (height 80 and $70 \mathrm{~mm}$ ) were fastened by the rail fastenings on the concrete block which simulates the slab. The influence of coil springs of the floating slab is considered in the FEM results. Table 5 shows the process of loading. The load condition is as given in Table 4. Figure 20 shows the measuring points of rail displacements.

\subsection{Test results}

Figures 21 and 22 show the rail tilting angles and rail head and base displacements. In Figs 21 and 22, the test results were compared with the FEM results described in Table 4. The FEM result and the test results of rail head displacements were in good agreement when $L_{A}$ and $L_{B}$ were applied in each case. As regards the rail base displacements obtained from both cases, the FEM result was 0.6 times of the test result when $L_{A}$ was applied and 0.4 times of

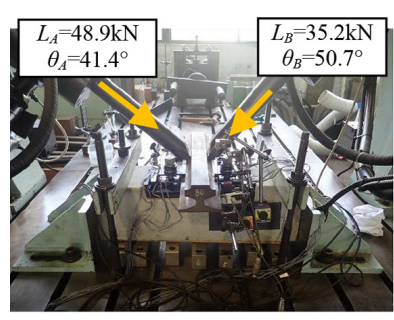

(a) Case 1 (Center of slab)

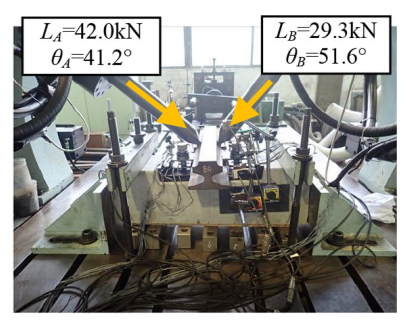

(b) Case 2 (Ends of slab)

Figure 19: Laboratory test specimen. 
Table 5: Load procedure.

\begin{tabular}{cll}
\hline Load procedure & Case 1 & Case 2 \\
\hline \multirow{2}{*}{ Preload } & $L_{A}: 0.0 \rightarrow 10.0$ & $L_{A}: 0.0 \rightarrow 5.0$ \\
& $L_{B}: 0.0 \rightarrow 10.0$ & $L_{B}: 0.0 \rightarrow 5.0$ \\
$L_{A}$ & $L_{A}: 10.0 \rightarrow 48.9 \rightarrow 10.0$ & $L_{A}: 5.0 \rightarrow 42.0 \rightarrow 5.0$ \\
& $L_{B}: 10.0$ (fixed) & $L_{B}: 10.0$ (fixed) \\
& $L_{A}: 10.0$ (fixed) & $L_{A}: 5.0$ (fixed) \\
$L_{B}$ & $L_{B}: 10.0 \rightarrow 35.2 \rightarrow 10.0$ & $L_{B}: 5.0 \rightarrow 29.3 \rightarrow 5.0$ \\
\hline
\end{tabular}

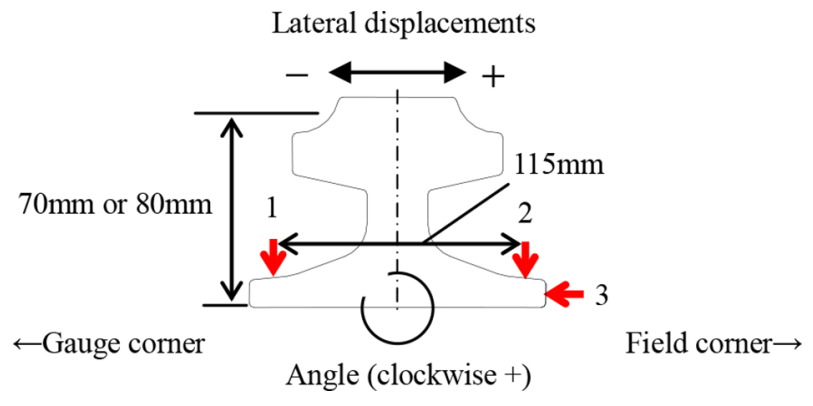

Figure 20: Position of measuring of rail displacements.

the test result when $L_{B}$ was applied. As for the rail tilting angle of Case 1, the FEM result was 1.5 times of the test result when $L_{A}$ was applied and 1.6 times of the test result when $L_{B}$ was applied. As for the rail tilting angle of Case 2, the FEM result was 1.4 times of the test result when $L_{A}$ was applied and 1.9 times of the test result when $L_{B}$ was applied. The cause of the differences has not been fully explained. It is deemed that the initial clamping force or torque variation owing to individual differences caused differences in the results.

From the above results, it is evident that the FEM results were substantially coincident with the test results. Therefore, it is concluded that the effectiveness of the determination method of load conditions for laboratory test based on the developed FEM model is verified. Furthermore, from the point of view of rail displacements and rail tilting angle, the loading applied on the ends of slab is stricter than that on the centre of the slab. Therefore, the laboratory test of the fastenings should be performed under the condition that the loading position is on the ends of slab.

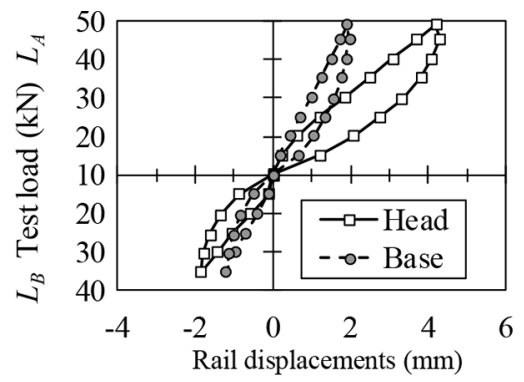

(a) Rail head and base displacements.

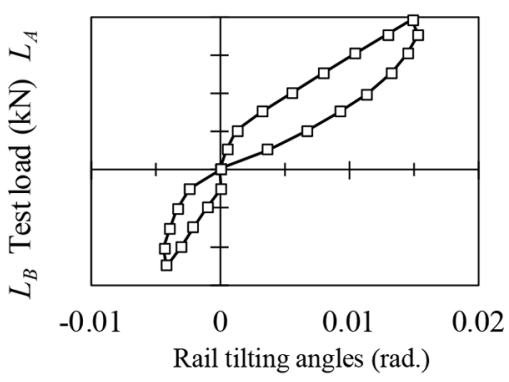

(b) Rail tilting angles.

Figure 21: Rail displacements and rail tilting angles of Case 1. 


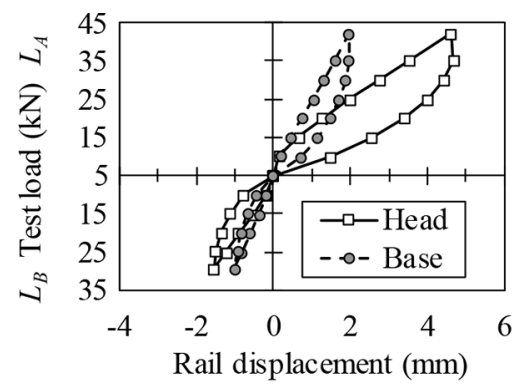

(a) Rail head and base displacements.

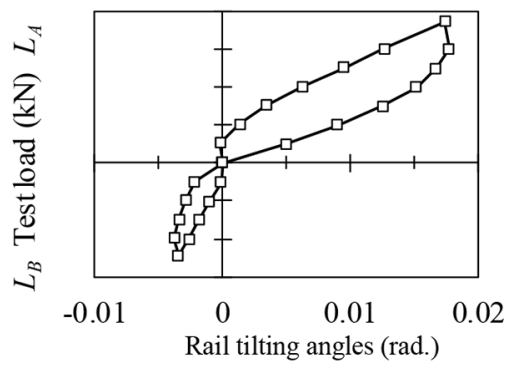

(b) Rail tilting angles.

Figure 22: Rail displacements and rail tilting angles of Case 2.

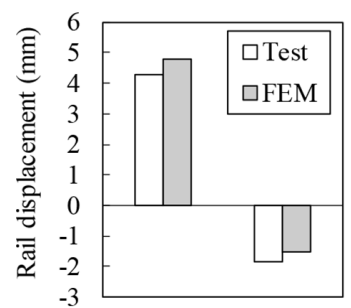

(a) Rail head displacement.

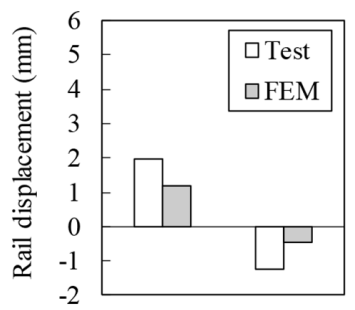

(b) Rail base displacement.

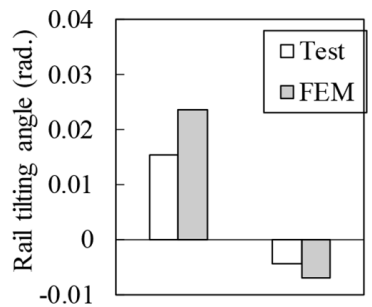

(c) Rail tilting angle.

Figure 23: FEM results and TEST results of Case 1.

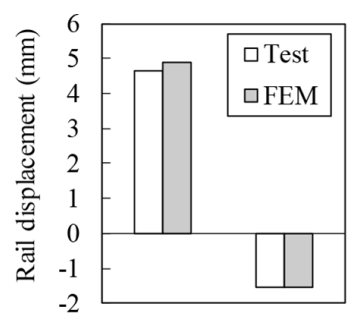

(a) Rail head displacement.

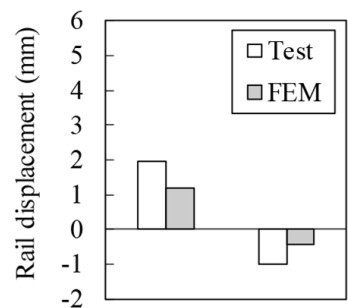

(b) Rail base displacement

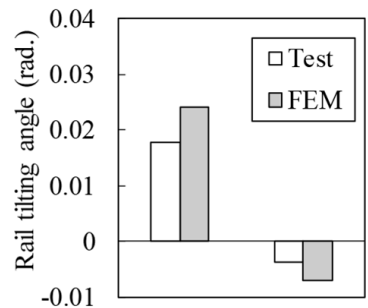

(c) Rail tilting angle.

Figure 24: FEM results and TEST results of Case 2.

\section{CONCLUSION}

In this paper, the author proposes the FEM model of a floating slab track and examines the determination method of load conditions for laboratory test of the rail fastenings. The research summary is as follows:

a. FEM model of a floating slab track is proposed to calculate the vertical and lateral rail pressures and rail tilting moments. In addition, the determination method of load conditions for the laboratory test of rail fastenings is examined by using the analytical results of the FEM model.

b. It is clear that the effectiveness of the determination method of load conditions for laboratory test based on the proposed FEM model is verified and is appropriate for evaluating the performance of the rail fastenings.

c. The loading applied on the ends of slab is stricter than that on the centre of the slab. The 
laboratory test of the fastenings should be performed under the condition that the loading position is on the ends of slab.

\section{REFERENCES}

[1] Railway Technical Research Institute. Design Standards for Railway Structures and Commentary (Track Structures), Maruzen, 2012.

[2] Youichi, H., A practical solution for the torsion (tilting) of rail. Journal of Japan Society of Civil Engineering, 210, pp. 33-46, 1973. https://doi.org/10.2208/ jscej1969.1973.210_33

[3] Yutaka, S., On the lateral strength of railway track. Railway Technical Research Report, Railway Technical Research Institute, 110, 1960.

[4] Takeshi, Y., Shizuya, U. \& Toshiyuki, K., Relationship between spring coefficient of fastening device and rail overturning angle. Quarterly Reports, Railway Technical Research Institute, 22(4), pp. 153-156, 1981.

[5] Shingo, T., Hiroo, K. \& Tadashi, D., Practical model for rail tilting and its application to performance test of rail fastening system. Journal of JSCE, 7, pp. 1-14, 2019.

[6] Tadashi, D., Shingo, T., Masato, N., \& Hiroo, K. Improving the performance of rail fastening system evaluation. Quarterly Report, Railway Technical Research Institute, 59(3), 2018.

[7] Japan Railway Construction Public Corporation. Construction of Rinkai Line, 2003.

[8] Shingo, T., Calculation method of load conditions for performance test of rail fastenings of a floating slab track. WIT Transactions on the Built Environment, WIT Press, 2020, ISSN 1743-3509.

[9] Railway Technology Promotion Center, Test procedures for rail fastening systems, 2020. 